\title{
Enrichment of a Novel Marine Ammonia-Oxidizing Archaeon Obtained from Sand of an Eelgrass Zone
}

\author{
NAOKi MATSUTANi ${ }^{1}$, TATSUnORI NAKAGAWA ${ }^{2 *}$, KYOKO NAKAMURA $^{1}$, REIJI TAKAHASHI ${ }^{2}$, KIYOSHI YOSHIHARA $^{2}$, and \\ TATSUAKI TOKUYAMA ${ }^{2}$ \\ ${ }^{1}$ Graduate School of Bioresource Sciences, Nihon University, 1866 Kameino, Fujisawa, Kanagawa 252-0880, Japan; \\ and ${ }^{2}$ College of Bioresource Sciences, Nihon University, 1866 Kameino, Fujisawa, Kanagawa 252-0880, Japan
}

(Received August 6, 2010—Accepted September 30, 2010—Published online November 30, 2010)

Ammonia-oxidizing archaea (AOA) are generally cultivated at ammonium concentrations of less than $2 \mathrm{mM}$. The physiology and abundance in the environment of AOA suggest an important role in the nitrogen cycle. We report here a novel marine ammonia-oxidizing crenarchaeote, strain NM25 belonged to 'Candidatus Nitrosopumilus', that was enriched from coastal sand of an eelgrass zone and grew in a medium containing $15 \mathrm{mM}$ ammonium at $30^{\circ} \mathrm{C}$. A phylogenetic analysis based on the 16S rRNA gene revealed this crenarchaeote was related to the ammonia-oxidizing archaeon 'Candidatus Nitrosopumilus maritimus' strain SCM1, with 98.5\% identity. The ammonia monooxygenase subunit A $($ amoA) gene of strain NM25 was less closely related to that of known cultivable AOA (>95\%) and environmental clones $(>97 \%)$. This finding suggests the existence of AOA adapted to high ammonium-containing environments.

Key words: ammonia-oxidizing archaea, marine crenarchaeote, nitrifying archaea, enrichment culture, 'Nitrosopumilus'

Ammonia-oxidizing bacteria (AOB) able to convert ammonium $\left(\mathrm{NH}_{4}^{+}\right)$to nitrite $\left(\mathrm{NO}_{2}^{-}\right)$have been considered solely responsible for the first and rate-limiting steps of nitrification in marine environments since the discovery of the marine ammonia-oxidizer Nitrosococcus marina (46). Ammonia monooxygenase catalyzes the conversion of ammonia $\left(\mathrm{NH}_{3}\right)$ to hydroxylamine $\left(\mathrm{NH}_{2} \mathrm{OH}\right)$ and is a key enzyme for nitrification (6). Several ammonia-oxidizers belonging to the genera Nitrosospira and Nitrosomonas within Betaproteobacteria $(26,30)$ and the genus Nitrosococcus within Gammaproteobacteria (2) have already been isolated from marine environments. However, microorganisms within Crenarchaeota Group 1.1a (Marine Crenarchaeota Group I) were recently found to be ammoniaoxidizers based on metagenomic studies of seawater (45) and the isolation of an archaeon, 'Candidatus Nitrosopumilus maritimus' strain SCM1, from a marine aquarium tank (25). Crenarchaeota Group 1.1a are often detected in marine environments $(12,16)$, and dominate in the deep sea (24). To elucidate the ecology of ammonia-oxidizing archaea (AOA) in marine systems, enrichment cultures of a nitrifying crenarchaeote were established from sea water (48) and estuarial sediment $(31,40)$. Moreover, recent molecular ecological studies based on the putative ammonia monooxygenase A subunit gene (amoA) have demonstrated the worldwide distribution of AOA in coastal, estuarial and deep-sea water and sediment, suggesting that AOA as well as AOB play an important role in the nitrogen cycle of a marine ecosystem (ex. 5, 7, 8, 15, 31, 33).

An archaeon, 'Candidatus Nitrosopumilus maritimus' SCM1, was sustainable with a low ammonium concentration

\footnotetext{
* Corresponding author. E-mail: nakatats@brs.nihon-u.ac.jp;

Tel: +81-466-84-3359; Fax: +81-466-84-3359.
}

(less than $1 \mathrm{mM}$ ) in the medium (25), and able to utilize a very low concentration of ammonium (29). Similarly, enrichment cultures of marine and freshwater AOA (31, 40, 48), thermophilic ammonia-oxidizers, 'Candidatus Nitrosocaldus yellowstonii' (44) and 'Candidatus Nitrososphaera gargensis' (19), derived from terrestrial hot springs, were also maintained at a low concentration of ammonium. Additionally, putative crenarchaeotal amo $A$ genes have been detected in low ammonium-containing environments such as sea-water, sediment and hot springs ( $<1 \mathrm{mM}$ ammonium) (14). However, amoA genes were also found in bioreactors with ammonium concentrations ranging from 1.2 to $3.2 \mathrm{mM}$ (36). As yet, there is a little information on the cultivation of AOA compared to AOB. Here we report the culture of a novel marine ammonia-oxidizing archaeon maintained at a high ammonium concentration.

\section{Materials and Methods}

\section{Sample collection}

Sand samples were collected about $0-5 \mathrm{~cm}$ below the seafloor by divers using sterile plastic tubes $(50 \mathrm{~mL})$ in the eelgrass zone in Tanoura Bay of Shimoda, Shizuoka, Japan, on 17 May, 2007. The temperature of the sea water was $18.5^{\circ} \mathrm{C}$. The concentration of ammonium in pore water was $558 \mu \mathrm{M}$. It has been previously suggested that AOA were responsible for nitrification in the eelgrass zone as well as ammonia-oxidizing bacteria (AOB) (5). The samples were stored at $4^{\circ} \mathrm{C}$ and transferred to the laboratory that same day.

\section{Cultivation of marine $A O A$}

One gram of sample was diluted with $10 \mathrm{~mL}$ of modified ASWmedium (33). This suspension was thoroughly mixed and serially diluted (10-fold), and test tubes (inner diameter, $14 \mathrm{~mm}$ ) were incubated at 10,20 and $30^{\circ} \mathrm{C}$ in the dark without shaking. The medium contained $\left(\mathrm{NH}_{4}\right)_{2} \mathrm{SO}_{4} 1.0 \mathrm{~g}, \mathrm{NaCl} 5.84 \mathrm{~g}, \mathrm{MgCl}_{2} \cdot 6 \mathrm{H}_{2} \mathrm{O} 10 \mathrm{~g}, \mathrm{Na}_{2} \mathrm{SO}_{4}$ 
$3.91 \mathrm{~g}, \mathrm{CaCl}_{2} 1.1 \mathrm{~g}, \mathrm{KCl} 0.66 \mathrm{~g}, \mathrm{NaHCO}_{3} 0.19 \mathrm{~g}, \mathrm{~K}_{2} \mathrm{HPO}_{4} 0.01 \mathrm{~g}$ Fe(III)-EDTA $0.01 \mathrm{~g}$, MOPS [3-( $N$-morpholino) propanesulfonic acid] $10 \mathrm{~g}$, and $1 \mathrm{~mL}$ of bromothymol blue solution (bromothymol blue $0.01 \mathrm{~g} \mathrm{~L}^{-1}, \mathrm{Na}_{2} \mathrm{HPO}_{4} 0.095 \mathrm{~g} \mathrm{~L}^{-1}$, and $\mathrm{KH}_{2} \mathrm{PO}_{4} 0.005 \mathrm{~g} \mathrm{~L}^{-1}$ in distilled water) in $1,000 \mathrm{~mL}$ of distilled water. The $\mathrm{pH}$ of the medium was adjusted to 8.0. The highest dilution at which nitrite production was observed was serially diluted (10-fold) with the medium and incubated. After this step was repeated four times, the following were added to one liter of the modified ASW-medium for a $30^{\circ} \mathrm{C}$-incubation: $1 \mathrm{~mL}$ of a nonchelated trace element mixture (47), $1 \mathrm{~mL}$ of a selenite-tungstate solution $\left(0.4 \mathrm{~g} \mathrm{~L}^{-1} \mathrm{NaOH}, 6 \mathrm{mg}\right.$ $\left.\mathrm{L}^{-1} \mathrm{Na}_{2} \mathrm{SeO}_{3} \cdot 5 \mathrm{H}_{2} \mathrm{O}, 8 \mathrm{mg} \mathrm{L}-1 \mathrm{Na}_{2} \mathrm{WO}_{4} \cdot 2 \mathrm{H}_{2} \mathrm{O}\right), 1 \mathrm{~mL}$ of a vitamin mixture $\left(40 \mathrm{mg} \mathrm{L}^{-1}\right.$ of 4-aminobenzoic acid, $10 \mathrm{mg} \mathrm{L}^{-1}$ of D-biotin, $100 \mathrm{mg} \mathrm{L}^{-1}$ of nicotinic acid, $50 \mathrm{mg} \mathrm{L}^{-1}$ of calcium D-pantothenate and $150 \mathrm{mg} \mathrm{L}^{-1}$ of pyridoxine dihydrochloride dissolved in $10 \mathrm{mM}$ sodium phosphate buffer [pH 7.1]), $1 \mathrm{~mL}$ of a thiamin solution $(100$ $\mathrm{mg} \mathrm{L}^{-1}$ of thiamine chloride dihydrochloride dissolved in $25 \mathrm{mM}$ sodium phosphate buffer [pH 3.4]) and $1 \mathrm{~mL}$ of vitamin $\mathrm{B}_{12}$ solution $\left(50 \mathrm{mg} \mathrm{L} \mathrm{L}^{-1}\right.$ of cyanocobalamine dissolved in distilled water). Cultures were routinely transferred $(10 \%$ volume per transfer) to fresh medium in test tubes (inner diameter, $14 \mathrm{~mm}$ ) when nitrite concentrations reached approximately $3 \mathrm{mM}$. Growth was monitored based on nitrite production, PCR-denaturing gradient gel electrophoresis (DGGE), and microscopy. The enrichment culture was sand-free and stable, resulting from repeated dilution for over two years.

For growth tests, test tubes $(22 \mathrm{~mm})$ containing $30 \mathrm{~mL}$ of modified ASW-medium were used. The concentration of ammonium was adjusted to $15 \mathrm{mM}$ or $26 \mathrm{mM}$. To test the tolerance to ammonium in the enrichment cultures, test tubes $(14 \mathrm{~mm})$ with 10 $\mathrm{mL}$ of modified ASW-medium were used. The concentration of ammonium in the medium was adjusted to $0.8,12,26,36,47,61$ or $76 \mathrm{mM}$.

\section{Chemical analyses}

The concentration of nitrite in the culture medium was determined colorimetrically with Griess-Ilosvey reagent (20). The concentration of ammonium was determined colorimetrically by a modified indophenol reaction (23). The concentration of nitrate was measured with an ion-chromatography system-1000 attached to an UltiMate 3000 Variable Wavelength Detector (Dionex, Sunnyvale, CA).

\section{Fluorescence in situ hybridization}

For fluorescence in situ hybridization (FISH), cells were collected with $0.2-\mu \mathrm{m}$-pore-size polycarbonate GTBP membrane filters (Millipore, Billerica, MA, USA) and fixed in $2 \%$ paraformaldehyde. The fixed cell suspensions were spotted on precleaned, gelatin-coated microscopic slides. Dehydration and in situ hybridization were performed according to the procedure described by Amann et al. (4). The following 16S rRNAtargeted oligonucleotides were used: a Cy3-labeled CREN500nm probe for strain NM25 belonged to 'Nitrosopumilus' (Table 1), a Cy3-labeled ARCH915 probe for the domain Archaea (41) and an FITC-labeled EUB338 probe for the domain Bacteria (3). The CREN500nm probe was modified from CREN499R for the kingdom Crenarchaeota (9). Cell numbers of CREN500nm- or EUB338-stained microbes were determined by counting cells in more than 3 microscopic fields per sample, each of which contained more than 50 DAPI-stained cells. The specificity of the labeling was confirmed by a failure to hybridize Pyrobaculum aerophilum NBRC $100827^{\mathrm{T}}$ and Nitrosospira multiformis ATCC $25196^{\mathrm{T}}$. For counting total cell numbers, the cells were fixed in $2 \%$ paraformaldehyde and stained with 4',6'-diamidino-2-phenylindole (DAPI). The cells were filtrated on $0.2-\mu \mathrm{m}$ polycarbonate GTBP membrane filter. The total cell counts were estimated from 5 microscopic fields per sample.

16S rRNA and amoA sequences and phylogenetic analysis

Cells were collected by centrifugation. Nucleic acids were then

Table 1. Oligonucleotides used for FISH and the 16S rRNA sequences of target and nontarget species

Probe, target and nontarget organism(s), and environmental clones

CREN500Rnm 3'-CCC CAC CCG TTC AAG ACC-5'

'Nitrosopumilus sp.' NM25 5'-GGG GUG GGC AAG UUC UGG-3 '

'Nitrosopumilus maritimus' 5 '-GGG GUG GGC AAG UUC UGG-3' SCM1

'Cenarchaeum symbiosum' 5'-GGG GUG GGC AAG UUC UGG-3 '

Marine fosmid

DeepAnt-EC39

5 '-GGG GUG GGC AAG UUC UGG-3'

'Nitrososphaera gargensis' 5'-GGG GUG GGC AAG U-C UGG-3 '

'Nitrosocaldus yellowstonii' 5 '-GGG GUG GGC AAG U-U UGG-3'

Pyrobaculum aerophilum IM2

Pyrodictium occultum

PL-19

'Nanoarchaeum equitans'

Kin4-M

EUB338

Bacteria

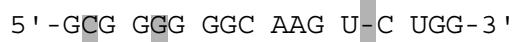

5 '-GCG GGG GGC AAG U-C UGG-3'

5'-GCG GUG GGC AAG A-G GGG-3

3'-TGA GGA TGC CCT CCG TCG-5'

a Formamide concentration in hybridization buffer was $20 \%$.

extracted with Lysing Matrix E (MP Biomedicals, Solon, OH, USA) and ISOPLANT II (Nippon Gene, Toyama, Japan). A near complete archaeal 16S rRNA gene was PCR amplified using archaeal-specific primers $\operatorname{Ar} 7 f(28)$ and Univ1492R (27) with the following protocol: $94^{\circ} \mathrm{C}$ for $5 \mathrm{~min}$ and then 30 cycles at $94^{\circ} \mathrm{C}$ for 1 $\min , 55^{\circ} \mathrm{C}$ for $1 \mathrm{~min}$ and $72^{\circ} \mathrm{C}$ for $1 \mathrm{~min}$, with a final extension at $72^{\circ} \mathrm{C}$ for $9 \mathrm{~min}$. For PCR-DGGE, DNA fragments encoding $16 \mathrm{~S}$ rRNA genes were amplified using either primer sets ARC344F-GC and ARC915R for Archaea (11) or EUB341F-GC and 907R for Bacteria (32) with the protocol described above. Crenarchaeotal amoA was amplified using crenAMO $\mathrm{F}$ and crenAMO R (18), again with the protocol described above. The betaproteobacterial amo $A$ gene was amplified using amoA-1F and $a m o A-2 \mathrm{R}$ (39). The gammaproteobacterial amo $A-a m o B$ gene was amplified using $a m o A-3 \mathrm{~F}$ and $a m o B-4 \mathrm{R}$ (38). Amplified fragments were cloned with a TOPO TA PCR cloning kit (Invitrogen, Carlsbad, USA) and sequenced with the primers M13F, M13R, Ar7f, ARC344F, ARC344R, A571F (10), ARC915F, ARC915R, Ar1384r (28), Univ1492R, EUB341F and 907R as described previously (34). The nucleotide and amino acid sequences were manually aligned using the CLUSTAL W program in MEGA4 (42) and Clustal X version 1.83 (43). Phylogenetic analyses were performed with neighbor-joining, maximum-parsimony and maximum-likelihood using MEGA4 and MOLPHY (1).

\section{Quantitative PCR}

Crenarchaeotal and betaproteobacterial amoA genes in culture medium were quantified by real-time PCR in a LightCycler system 350S (Roche Diagnostics, Mannheim, Germany) with a SYBR Premix Ex Taq (Perfect Real Time) kit (Takara Bio, Otsu, Japan) using either crenAMO_F/crenAMO_R or amoA-1F/amoA-2R (5, 34). Cycling conditions were as follows: for both amo $A$ genes, an initial denaturation step at $95^{\circ} \mathrm{C}$ for $30 \mathrm{sec}$ and then 35 cycles at $95^{\circ} \mathrm{C}$ for $15 \mathrm{sec}, 57^{\circ} \mathrm{C}$ for $15 \mathrm{sec}$ and $72^{\circ} \mathrm{C}$ for $30 \mathrm{sec}$. Fluorescence intensity was measured at $81{ }^{\circ} \mathrm{C}$. Plasmids containing copies of amoA genes of the crenarchaeotal clone G35259 (5) or $N$. multiformis ATCC $25196^{\mathrm{T}}$ were used to make a standard curve.

\section{Nucleotide sequence accession numbers}

The 16S rRNA and amoA gene sequences were submitted to $\mathrm{DDBJ} / \mathrm{EMBL} / \mathrm{GenBank}$ and have been assigned the following accession numbers: AB546961-AB546965. 


\section{Results and Discussion}

\section{Establishment of enrichment cultures}

An ammonia-oxidizing enrichment culture derived from coastal sand, that was sediment-free and stable, was first established at $30^{\circ} \mathrm{C}$ by repeated passage into modified ASW-medium containing ammonium sulfate $(7.6 \mathrm{mM})$ and bicarbonate $(2.3 \mathrm{mM})$ as a sole source of energy and carbon for more than two years. The crenarchaeotal amo $A$ gene was successfully amplified from only the $30^{\circ} \mathrm{C}$-incubated tubes after four rounds of serial dilution without any amplification of the bacterial amoA gene. However, the proportion of archaeal microbes among all prokaryotes was estimated at $0.02 \%$ in medium at the highest dilution tube where nitrite production was observed, using quantitative PCR based on 16S rRNA. The archaeal microbes were highly abundant after the two years. It was reported that AOA medium required vitamins and trace elements (25). In this study too, it was necessary to supplement the medium with trace elements and vitamins to maintain the enrichment after serial dilution. In addition, the enrichment of 'Candidatus Nitrosopumilus'-like archaea was successful on the transfer of $10 \%$ inoculum into fresh medium in glass tubes instead of Erlenmeyer flasks. It seems that using a test tube for cultivation of AOA inhibited the growth of heterotrophic microbes due to a decrease in the amount of oxygen diffused into the medium. The enrichment culture was stable in test tubes (inner diameter, $14 \mathrm{~mm}$ ) containing $7.6 \mathrm{mM}$ ammonium sulfate, trace metals, and vitamins. Although filtrations was performed for isolation, a pure culture has not yet been established. It is possible that AOA is maintained by an unknown compound released from microorganisms in the enrichment culture.

\section{Ammonium oxidation by crenarchaeote}

Tiny rod-shaped or peanut-shaped cells (diameter of 0.2 $0.4 \mu \mathrm{m}$ and length of $0.4-0.9 \mu \mathrm{m}$ ) stained by the CREN500nm probe for NM25 belonged to 'Nitrosopumilus' were observed as the dominant population throughout incubation of the enrichment NM25 culture under the epifluorescence microscope (Fig. 1A and Fig. 1B). Bacterial cells remained in the culture (Fig. 1C). Peanut-shaped cells $(<1 \mu \mathrm{m})$ were previously reported for an ammonia-oxidizing archaeon 'Candidatus Nitrosopumilus maritimus' SCM1 (25), a psychrophilic crenarchaeon 'Candidatus Cenarchaeum symbiosum' habitating a marine sponge (37) and marine planktonic archaeal cells (13). In addition, the 'Candidatus Nitrosopumilus'-like cells were smaller than the cells of the marine AOB Nitrosomonas aestuarii (1.0-1.3 by $1.4-2.0 \mu \mathrm{m})$ and Nitrosomonas marina $(0.7-0.9$ by $1.4-2.3$ $\mu \mathrm{m})$ (26). Although NM25 belonged to 'Nitrosopumilus' possessed the region of the $16 \mathrm{~S}$ rRNA gene sequence in which the ARCH915 probe for Archaea bound, the 'Candidatus Nitrosopumilus'-like cells were not labeled with this probe. Similarly, cells of the nanosized hyperthermophilic archaeon 'Candidatus Nanoarchaeum equitans', measuring approximately $0.4 \mu \mathrm{m}$ in diameter, were not labeled with the ARCH915 probe (21). However, after the CREN500nm probe was designed based on the 'Candidatus Nitrosopumilus' sequence, at the same position as the
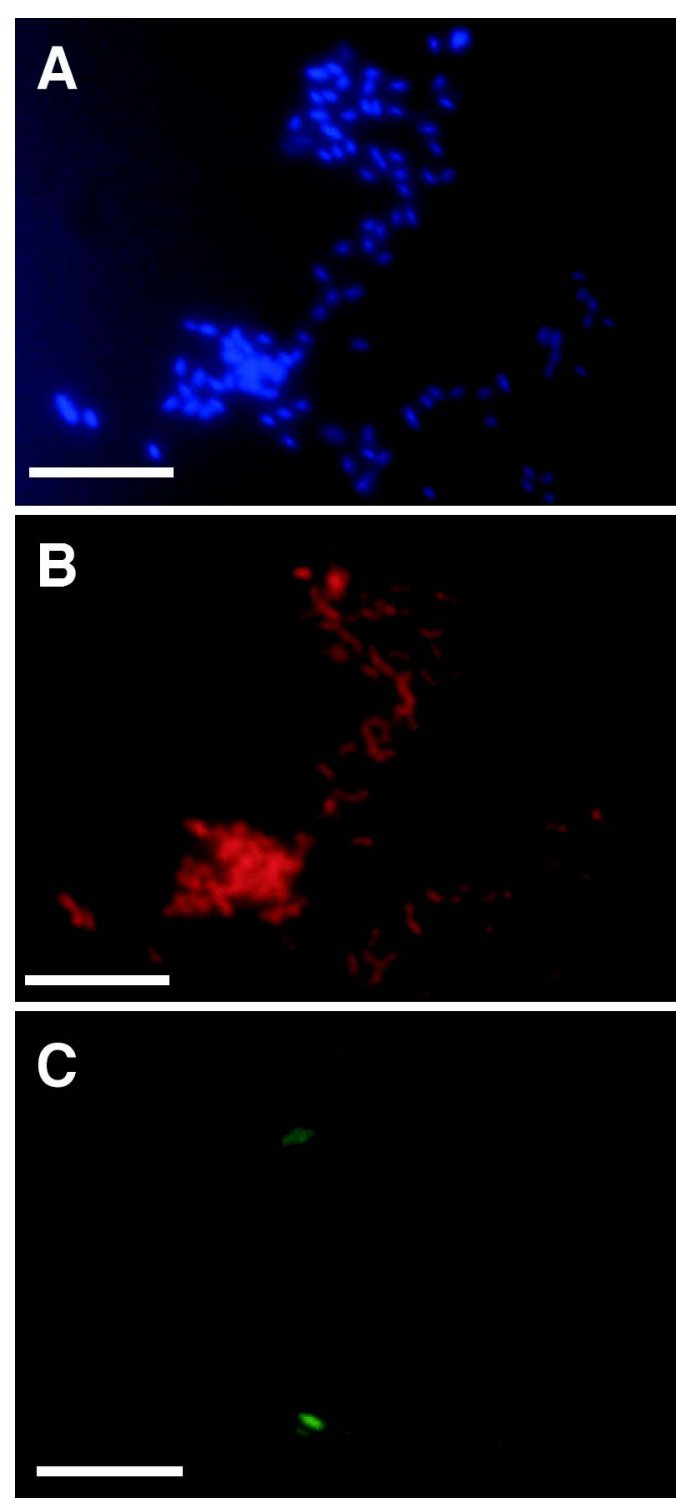

Fig. 1. Epifluorescence microscopy of the NM25 belonged to 'Nitrosopumilus' enrichment culture after 16 days of incubation. A, Fluorescence micrograph of cells stained with DAPI. B, Fluorescence micrograph of cells after hybridization with the Cy3-labeled probe CREN500nm ('Nitrosopumilus' strain NM25). C, Fluorescence micrograph of cells after hybridization with the FITC-labeled probe EUB338 (Bacteria). Scale bars represent $5 \mu \mathrm{m}$.

$515 \mathrm{mcR}$ probe for 'Candidatus Nanoarchaeum equitans' (Table 1), the 'Candidatus Nitrosopumilus'-like cells showed bright fluorescence (Fig. 1B). It is, therefore, likely that the position from 500 to 519 is the accessible binding site of the small-subunit rRNA for the nanosized archaeon.

Growth of microbes in the enrichment culture containing $26 \mathrm{mM}$ ammonium was associated with the consumption of ammonium accompanying the accumulation of nitrite (Fig. 2). Cell density ranged from $9.7 \times 10^{6}$ to $3.0 \times 10^{8}$ cells $\mathrm{mL}^{-1}$, with a minimum generation time of $48 \mathrm{~h}$. The maximal density of 'Candidatus Nitrosopumilus'-like cells was approximately ten times higher than previously reported cell densities of isolated and enriched AOA $(25,44,48)$. No nitrate was detected in the enrichment cultures.

FISH revealed that the ratio of cells stained by the 


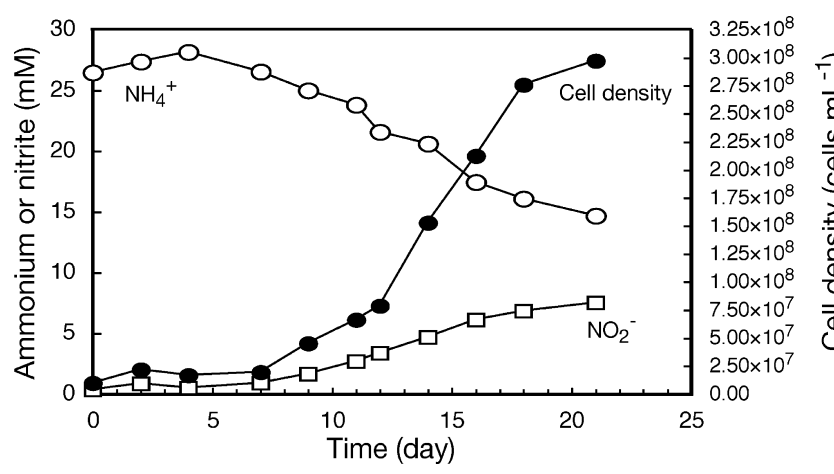

Fig. 2. Time-course of changes in ammonium and nitrite concentrations and concomitant cell growth in the enrichment culture of NM25 belonged to 'Nitrosopumilus' in test tubes (inner diameter $22 \mathrm{~mm}, n=3$ ) at $30^{\circ} \mathrm{C}$.
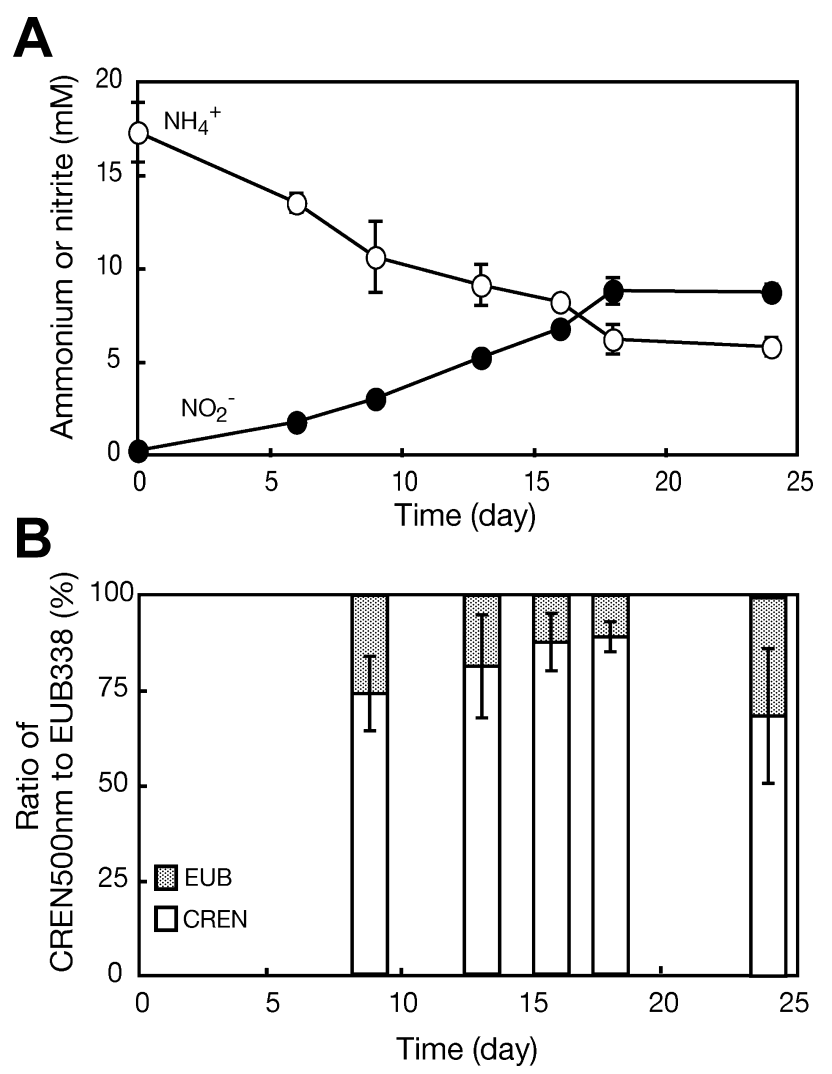

Fig. 3. Correlation of ammonia oxidation with growth of NM25 belonged to 'Nitrosopumilus'. A, Time-course of changes in ammonium and nitrite concentrations in the enrichment culture in test tubes (inner diameter $22 \mathrm{~mm}, n=3$ ) at $30^{\circ} \mathrm{C}$. B, Change in the ratio of NM25 belonged to 'Nitrosopumilus' (CREN500nm) to Bacteria (EUB338) cell counts in the same enrichment culture as determined by FISH. The ratio was estimated by the following formula $\%=$ CREN500nm or EUB338 (CREN500nm+EUB338) $)^{-1} \times 100$. Error bars represent the standard deviation of the mean.

CREN500nm probe for NM25 belonged to 'Nitrosopumilus' increased gradually from 9- to 18-days' incubation (reaching $89 \%$ ) accompanying the increase in nitrite (Fig. 3). Of all the cells stained by DAPI $(n=1304), 89.9 \pm 10.2 \%(n=3)$ yielded a positive signal with the CREN500nm probe after 18-days' incubation. The molar ratio of oxidation of ammonium to nitrite (nitrite ammonium $^{-1}$ ) was 0.8 after 18 days of incubation. It is assumed that $1.0 \mathrm{mmol}$ of nitrite is formed per

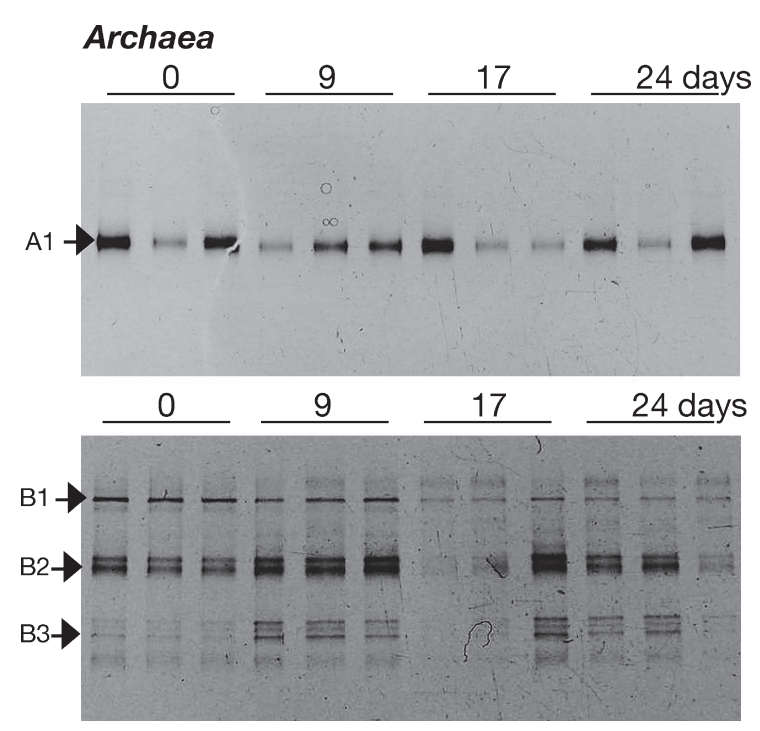

Bacteria

Fig. 4. Denaturing gradient gel electrophoresis of archaeal and bacterial communities in the enrichment culture of NM25 belonged to 'Nitrosopumilus'. 16S rRNA gene fragments were amplified with primer sets for the domain Archaea or Bacteria.

mmol of ammonium, according to the following equation for complete oxidation of ammonium: $\mathrm{NH}_{4}^{+}+1.5 \mathrm{O}_{2} \rightarrow \mathrm{NO}_{2}{ }^{-}$ $+\mathrm{H}_{2} \mathrm{O}+2 \mathrm{H}^{+}$. Indeed, $0.8 \mathrm{mmol}$ of nitrite was formed per mmol of ammonium. This measured oxidation balance is similar to the above stoichiometry. It seems that part of the ammonium was utilized by archaea and bacteria. The ammonium oxidation rate of the 'Candidatus Nitrosopumilus'-like cells in the enrichment culture $\left(0.19-0.43 \mathrm{fmol} \mathrm{NH}_{4}^{+}\right.$cell-1 $\mathrm{h}^{-1}$ ) was similar to the range of rates estimated for pure and enrichment cultures of known AOA, 0.08-0.59 fmol $\mathrm{NH}_{4}{ }^{+}$cell $^{-1} \mathrm{~h}^{-1}(22)$.

The DGGE profile retrieved from the enrichment culture consisted of a single dominant archaeal 16S rDNA band (A1) during incubation (Fig. 4). The sequence of this band corresponded to that of NM25 belonged to 'Nitrosopumilus' (Fig. 5). The sequences of bacterial DGGE bands (B1, B2 and B3) were non-AOB (marine chemoorganotrophic bacteria Neptuniibacter and Marinobacter spp. and bacteria within the Deltaproteobacteria), indicating that marine bacteria utilized organic matter released by AOA. Moreover, quantitative PCR also revealed that the abundance of the crenarchaeotal amoA gene increased with the production of nitrite in the enrichment cultures (reaching $4.3 \times 10^{8}$ copies $\mathrm{mL}^{-1}$ ). However, neither betaproteobacterial nor gammaproteobacterial amo $A$ was detected in the enrichment cultures. Thus, these results demonstrated that ammonium was converted to nitrite by a single population of crenarchaeote NM25 belonged to 'Nitrosopumilus' in the enrichment culture.

\section{Phylogenetic analysis of 'Candidatus Nitrosopumilus sp.' strain NM25}

Analysis of the 16S rRNA gene revealed that NM25 belonged to Crenarchaeota Group 1.1a (Fig. 5). NM25 was most closely related to 'Candidatus Nitrosopumilus maritimus' SCM1 (25) and the environmental clone SAT 3E6 


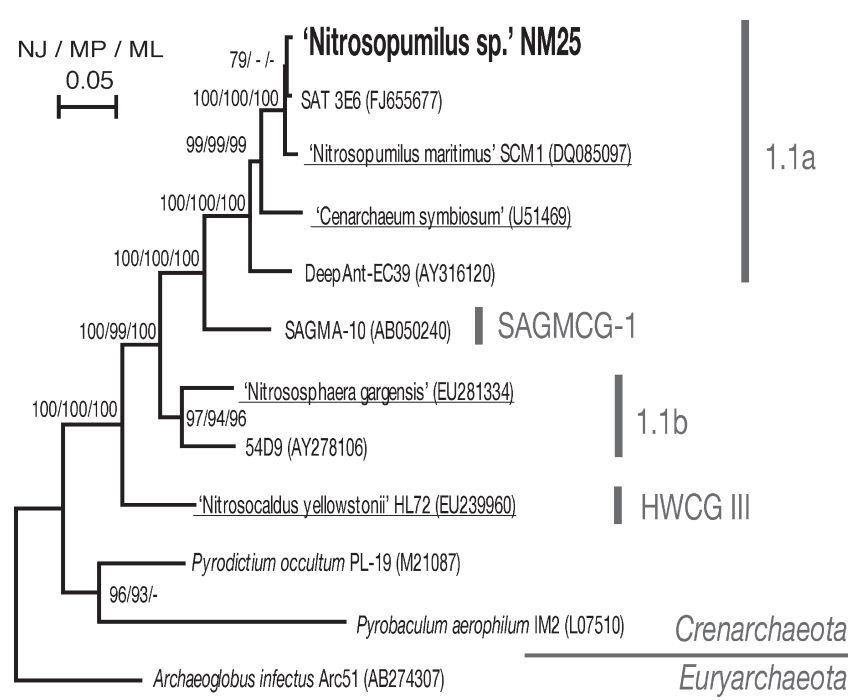

Fig. 5. Phylogenetic analysis of archaeal $16 \mathrm{~S}$ rRNA gene sequences (1,352 bases) amplified from NM25 belonged to 'Nitrosopumilus'. The underline represents cultivable ammonia-oxidizing archaea. The tree was constructed with the neighbor-joining method. The scale bar represents an estimated sequence divergence of 5\%. Neighbor-joining (left), maximum-parsimony (center) and maximum-likelihood (right) bootstrap values providing more than $50 \%$ support are indicated.

obtained from salt marsh sediment (35), with $98.5 \%$ and $99.4 \%$ identity, respectively. Analysis of the amo $A$ gene revealed that NM25 belonged to the Marine cluster containing AOA enriched from estuarial sediment (31), the ammonia-oxidizing archaeon 'Candidatus Nitrosopumilus maritimus' SCM1 (25) and the psychrophilic crenarchaeon 'Candidatus Cenarchaeum symbiosum' (37), with sequence similarity of $<95 \%, 94 \%$ and $74 \%$, respectively (Fig. S1). In addition, the amo $A$ gene sequence of NM25 was less closely related to that of known environmental clones ( $>97 \%)$. These results suggest that the ammonia-oxidizing archaeon NM25 belonged to 'Nitrosopumilus' was a novel species within Crenarchaeota Group 1.1a.

\section{Ammonium tolerance}

In general, AOA are known for their high sensitivity to their substrate ammonium $(25,29,31,40,48)$. The known culturable AOA were maintained at less than $2 \mathrm{mM}$ of ammonium independent of sampling sites (Table 2). However, the enrichment culture of NM25 belonged to 'Nitrosopumilus' was able to grow in the presence of 26 $\mathrm{mM}$ ammonium within the test tube (inner diameter $22 \mathrm{~mm}$ )
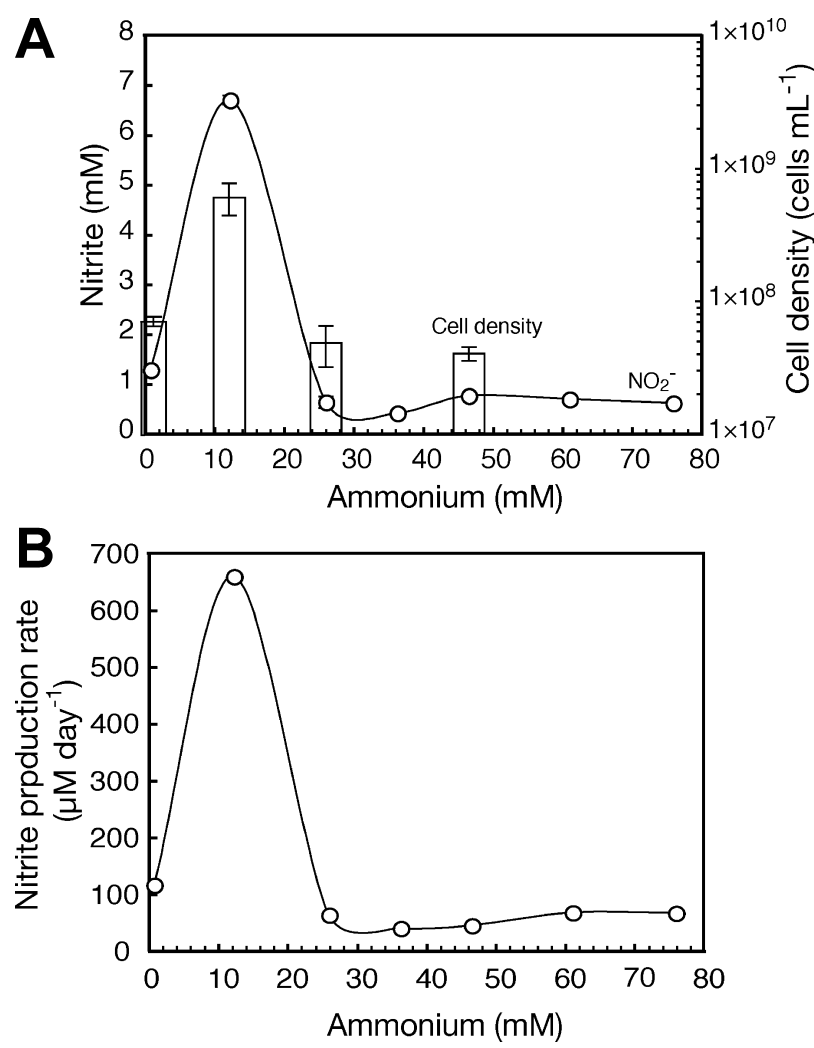

Fig. 6. Tolerance to ammonium of the NM25 enrichment culture in test tubes (inner diameter $14 \mathrm{~mm}, n=3$ ) at $30^{\circ} \mathrm{C}$. A, The nitrite concentration and cell density after 30 days of incubation. Error bars represent the standard deviation of the mean. $\mathrm{B}$, The maximum production rate of nitrite per day is plotted against the ammonium concentration.

(Fig. 2). In addition, the optimal ammonium concentration for NM25 was approximately $15 \mathrm{mM}$ in the test tube (14 $\mathrm{mm}$ ) (Fig. 6). A concentration of more than $35 \mathrm{mM}$ of ammonium resulted in an almost complete inhibition of growth.

\section{Ecological observation}

No $a m o A$ gene sequence closely related to that of the archaeon NM25 belonged to 'Nitrosopumilus' was obtained in sand of an eelgrass zone in a previous study (5), although NM25 was derived from the same sampling site. This result suggests that NM25 was a minor population in the in situ habitats of an eelgrass zone. The enrichment culture of archaeon NM25 was established at $15 \mathrm{mM}$ ammonium. However, the concentrations of ammonium in sand samples

Table 2. Culture conditions that differentiate NM25 belonged to 'Nitrosopumilus' from other ammonia-oxidizing archaea

\begin{tabular}{lccl}
\hline \multicolumn{1}{c}{ Isolate or enrichment culture } & Ammonium $(\mathrm{mM})$ & Temperature $\left({ }^{\circ} \mathrm{C}\right)$ & \multicolumn{1}{c}{ Source of inoculum } \\
\hline 'Nitrosopumilus sp.' NM25 & $15^{\mathrm{a}}, 26^{\mathrm{b}}$ & 30 & Coastal sand of an eelgrass zone \\
'Nitrosopumilus maritimus' SCM1 & $0.5-1.0$ & 28 & Rocky substratum of a tropical marine tank \\
Enrichment cultures & 0.5 & 22 & Sediments of estuary \\
Enrichment cultures & 0.15 & 25 & Sea water \\
Enrichment cultures & 2.0 & 20 & Freshwater coastal sediments \\
'Nitrososphaera gargensis' & 2.0 & 46 & Microbial mat of terrestrial hot spring \\
'Nitrosocaldus yellowstonii' & $0.5-1.0$ & $65-72$ & Sediment of terrestrial hot spring \\
\hline
\end{tabular}

a The value was obtained from the test tube (inner diameter $14 \mathrm{~mm}$ ).

$\mathrm{b}$ The value was obtained from the test tube (inner diameter $22 \mathrm{~mm}$ ). 
of the eelgrass zone were $<1 \mathrm{mM}$ (5). It would seem that the difference in ammonium levels led to the cultivation of a novel ammonia-oxidizing archaeon, which adapted to a higher concentration of ammonium than known AOA. On the other hand, putative crenarchaeotal amo $A$ genes were usually obtained at less than $1 \mathrm{mM}$ ammonium in nature (14). It is therefore likely that the growth of major members of AOA within sand of the eelgrass zone was inhibited by the higher concentration of ammonium in the culture medium.

\section{Conclusion}

We showed for the first time that a novel marine ammonium-oxidizing archaeon, NM25 belonged to 'Nitrosopumilus', within Crenarchaeota Group 1.1a, was successfully enriched at a high ammonium concentration from coastal sand of an eelgrass zone. This finding suggests that AOA distribute not only in low ammonia-containing environments but also in high ammonia-containing environments. A marine ammonia-oxidizing archaeon, 'Candidatus Nitrosopumilus maritimus' SCM1, and a thermophilic ammonia-oxidizing archaeon, 'Candidatus Nitrosocaldus yellowstonii', were reported to be obligate autotrophs (25, 44). On the other hand, a psychrophilic marine crenarchaeon, 'Candidatus Cenarchaeum symbiosum', was suggested to be an obligate autotroph or a mixotroph utilizing both carbon dioxide and organic maters $(17,18)$. Further study is needed to determine whether the archaeon NM25 belonged to 'Nitrosopumilus' is an obligate autotroph or a mixotroph.

\section{Acknowledgements}

We wish to thank the staff of the General Research Institute (Nihon University) for their support with the sequencing. This study was supported by a grant from the Ministry of Education, Culture, Sports, Science and Technology KAKENHI to T.N. (21770028), a Nihon University Grant for Assistants and Young Researchers 2007 (to T.N.) and the College of Bioresource Sciences Fund for Research Projects 2008-2009 (to K.Y.).

\section{References}

1. Adachi, J., and M. Hasegawa. 1995. Improved dating of the human chimpanzee separation in the mitochondrial-DNA tree: Heterogeneity among amino-acid sites. J. Mol. Evol. 40:622-628.

2. Alzerreca, J.J., J.M. Norton, and M.G. Klotz. 1999. The amo operon in marine, ammonia-oxidizing $\gamma$-proteobacteria. FEMS Microbiol. Lett. 180:21-29.

3. Amann, R.I., B.J. Binder, R.J. Olson, S.W. Chisholm, R. Devereux, and D.A. Stahl. 1990. Combination of 16S rRNA-targeted oligonucleotide probes with flow cytometry for analyzing mixed microbial populations. Appl. Environ. Microbiol. 56:1919-1925.

4. Amann, R.I., I. Krumholz, and D.A. Stahl. 1990. Fluorescentoligonucleotide probing of whole cells for determinative, phylogenetic, and environmental studies in microbiology. J. Bacteriol. 172:762-770.

5. Ando, Y., T. Nakagawa, R. Takahashi, K. Yoshihara, and T. Tokuyama. 2009. Seasonal changes in abundance of ammoniaoxidizing archaea and ammonia-oxidizing bacteria and their nitrification in sand of an eelgrass zone. Microbes Environ. 24:21-27.

6. Arp, D.J., L.A. Sayavedra-Soto, and N.G. Hommes. 2002. Molecular biology and biochemistry of ammonia oxidation by Nitrosomonas europaea. Arch. Microbiol. 178:250-255.

7. Beman, J.M., and C.A. Francis. 2006. Diversity of ammoniaoxidizing archaea and bacteria in the sediments of a hypernutrified subtropical estuary: Bahía del Tóbari, Mexico. Appl. Environ. Microbiol. 72:7767-7777.
8. Beman, J.M., B.N. Popp, and C.A. Francis. 2008. Molecular and biogeochemical evidence for ammonia oxidation by marine Crenarchaeota in the Gulf of California. ISME J. 2:429-441.

9. Burggraf, S., T. Mayer, R. Amann, S. Schadhauser, C.R. Woese, and K.O. Stetter. 1994. Identifying members of the domain Archaea with rRNA-targeted oligonucleotide probes. Appl. Environ. Microbiol. 60:3112-3119.

10. Casanueva, A., N. Galada, G.C. Baker, et al. 2008. Nanoarchaeal 16S rRNA gene sequences are widely dispersed in hyperthermophilic and mesophilic halophilic environments. Extremophiles 12:651-656.

11. Casamayor, E.O., H. Schäfer, L. Bañeras, C. Pedrós-Alió, and G. Muyzer. 2000. Identification of and spatio-temporal difference between microbial assemblages from two neighboring sulfur lakes: Comparison by microscopy and denaturing gradient gel electrophoresis. Appl. Environ. Microbiol. 66:499-508.

12. DeLong, E.F. 1992. Archaea in coastal marine environments. Proc. Natl. Acad. Sci. USA 89:5685-5689.

13. DeLong, E.F., L.T. Taylor, T.L. Marsh, and C.M. Preston. 1999 Visualization and enumeration of marine planktonic archaea and bacteria by using polyribonucleotide probes and fluorescent in situ hybridization. Appl. Environ. Microbiol. 65:5554-5563.

14. Erguder, T.H., N. Boon, L. Wittebolle, M. Marzorati, and W. Verstraete. 2009. Environmental factors shaping the ecological niches of ammonia oxidizing archaea. FEMS Microbiol. Rev. 33:855-869.

15. Francis, C.A., K.J. Roberts, J.M. Beman, A.E. Santoro, and B.B. Oakley. 2005. Ubiquity and diversity of ammonia-oxidizing archaea in water columns and sediments of the ocean. Proc. Natl. Acad. Sci. USA 102:14683-14688.

16. Fuhrman, J.A., K. McCallum, and A.A. Davis. 1992. Novel major archaebacterial group from marine plankton. Nature 356:148-149

17. Hallam, S.J., K.T. Konstantinidis, N. Putnam, C. Schleper, Y. Watanabe, J. Sugahara, C. Preston, J. de la Torre, P.M. Richardson, and E.F. DeLong. 2006. Genomic analysis of the uncultivated marine crenarchaeote Cenarchaeum symbiosum. Proc. Natl. Acad. Sci. USA 103:18296-18301.

18. Hallam, S.J., T.J. Mincer, C. Schleper, C.M. Preston, K. Roberts, P.M. Richardson, and E.F. DeLong. 2006. Pathways of carbon assimilation and ammonia oxidation suggested by environmental genomic analyses of marine Crenarchaeota. PloS Biology 4:e95.

19. Hatzenpichler, R., E.V. Lebecleva, E. Spieck, K. Stoecker, A. Richter, H. Daims, and M. Wagner. 2008. A moderately thermophilic ammonia-oxidizing crenarchaeote from a hot spring. Proc. Natl. Acad. Sci. USA 105:2134-2139.

20. Hewitt, E.J., and D.J.D. Nicholas. 1964. Enzymes of inorganic nitrogen metabolism, p. 167-172. In H.F. Linskens, B.D. Sanwal, and M.V. Tracey (ed.), Modern Methods of Plant Analysis, vol. 7. Springer, Gottingen and Heidelberg, Germany.

21. Huber, H., M.J. Hohn, R. Rachel, T. Fuchs, V.C. Wimmer, and K.O Stetter. 2002. A new phylum of Archaea represented by a nanosized hyperthermophilic symbiont. Nature 417:63-67.

22. Jia, Z., and R. Conard. 2009. Bacteria rather than Archaea dominate microbial ammonia oxidation in an agricultural soil. Environ. Microbiol. 11:1658-1671.

23. Kandeler, E., and H. Gerber. 1988. Short-term assay of soil urease activity using colorimetric determination of ammonium. Biol. Fertil. Soils 6:68-72.

24. Karner, M.B., E.F. DeLong, and D.M. Karl. 2001. Archaeal dominance in the mesopelagic zone of the Pacific Ocean. Nature 409:507510 .

25. Könneke, M., A.E. Bernhard, J.R. de la Torre, C.B. Walker, J.B. Waterbury, and D.A. Stahl. 2005. Isolation of an autotrophic ammonia-oxidizing marine archaeon. Nature 437:543-546.

26. Koops, H.-P., B. Böttcher, U.C. Möller, A. Pommerening-Röser, and G. Stehr. 1991. Classification of eight new species of ammoniaoxidizing bacteria: Nitrosomonas communis sp. nov., Nitrosomonas ureae sp. nov., Nitrosomonas aestuarii sp. nov., Nitrosomonas marina sp. nov., Nitrosomonas nitrosa sp. nov., Nitrosomonas eutropha sp. nov., Nitrosomonas oligotropha sp. nov. and Nitrosomonas halophila sp. nov. J. Gen. Microbiol. 137:1689-1699.

27. Lane, D.J. 1991. 16S/23S rRNA sequencing, p. 115-175. In E. Stackebrandt and M. Goodfellow (ed.), Nucleic Acid Techniques in Bacterial Systematics. Wiley, New York, USA. 
28. Lueders, T., M. Manefield, and M.W. Friedrich. 2004. Enhanced sensitivity of DNA- and rRNA-based stable isotope probing by fractionation and quantitative analysis of isopycnic centrifugation gradients. Environ. Microbiol. 6:73-78.

29. Martens-Habbena, W., P.M. Berube, H. Urakawa, J.R. de la Torre, and D.A. Stahl. 2009. Ammonia oxidation kinetics determine niche separation of nitrifying Archaea and Bacteria. Nature 461:976-979.

30. Mizoguchi, M., J. Omotani, Y. Mizuno, R. Takahashi, T. Kanehira, M. Shinohara, and T. Tokuyama. 1998. Newly isolated marine ammonia-oxidizing bacterium, Nitrosomonas sp. TNO632. J. Ferment. Bioeng. 86:406-409.

31. Mosier, A.C., and C.A. Francis. 2008. Relative abundance and diversity of ammonia-oxidizing archaea and bacteria in the San Francisco Bay estuary. Environ. Microbiol. 10:3002-3016.

32. Muyzer, G., E.C. De Waal, and A.G. Uitterlinden. 1993. Profiling of complex microbial populations by denaturing gradient gel electrophoresis analysis of polymerase chain reaction-amplified gene coding for 16S rRNA. Appl. Environ. Microbiol. 59:695-700.

33. Nakagawa, T., K. Mori, C. Kato, R. Takahashi, and T. Tokuyama. 2007. Distribution of cold-adapted ammonia-oxidizing microorganisms in the deep-ocean of the northeastern Japan Sea. Microbes Environ. 22:365-372.

34. Nakaya, A., Y. Onodera, T. Nakagawa, K. Satoh, R. Takahashi, S. Sasaki, and T. Tokuyama. 2009. Analysis of ammonia monooxygenase and archaeal 16S rRNA gene fragments in nitrifying acid-sulfate soil microcosms. Microbes Environ. 24:168-174.

35. Nelson, K.A., N.S. Moin, and A.E. Bernhard. 2009. Archaeal diversity and the prevalence of Crenarchaeota in salt marsh sediments. Appl. Environ. Microbiol. 75:4211-4215.

36. Park, H.D., G.F. Wells, H. Bae, C.S. Criddle, and C.A. Francis. 2006. Occurrence of ammonia-oxidizing archaea in wastewater treatment plant bioreactors. Appl. Environ. Microb. 72:5643-5647.

37. Preston, C.M., K.Y. Wu, T.F. Molinski, and E.F. DeLong. 1996. A psychrophilic crenarchaeon inhabits a marine sponge: Cenarchaeum symbiosum gen. nov., sp. nov. Proc. Natl. Acad. Sci. USA 93:62416246.
38. Purkhold, U., A. Pommerening-Roser, S. Juretschko, M.C. Schmid, H.P. Koops, and M. Wagner. 2000. Phylogeny of all recognized species of ammonia oxidizers based on comparative 16S rRNA and amoA sequence analysis: implications for molecular diversity surveys. Appl. Environ. Microbiol. 66:5368-5382.

39. Rotthauwe, J.-H., K.-P. Witzel, and W. Liesack. 1997. The ammonia monooxygenase structural gene amo $A$ as a functional marker: Molecular fine-scale analysis of natural ammonia-oxidizing populations. Appl. Environ. Microbiol. 63:4704-4712.

40. Santoro, A.E., C.A. Francis, N.R. De Sieyes, and A.B. Boehm. 2008. Shifts in the relative abundance of ammonia-oxidizing bacteria and archaea across physicochemical gradients in a subterranean estuary. Environ. Microbiol. 10:1068-1079

41. Stahl, D.A., and R.I. Amann. 1991. Development and application of nucleic acids probes, p. 205-248. In E. Stackebrandt and M. Goodfellow (ed.), Nucleic Acid Techniques in Bacterial Systematics. Wiley, New York, N.Y.

42. Tamura, K., J. Dudley, M. Nei, and S. Kumar. 2007. MEGA4: Molecular Evolutionary Genetics Analysis (MEGA) software version 4.0. Mol. Biol. Evol. 24:1596-1599.

43. Thompson, J.D., T.J. Gibson, F. Plewniak, F. Jeanmougin, and D.G. Higgins. 1997. The CLUSTAL_X windows interface: Flexible strategies for multiple sequence alignment aided by quality analysis tools. Nucleic Acids Res. 25:4876-4882.

44. de la Torre, J.R., C.B. Walker, A.E. Ingalls, M. Könneke, and D.A. Stahl. 2008. Cultivation of a thermophilic ammonia oxidizing archaeon synthesizing crenarchaeol. Environ. Microbiol. 10:810-818.

45. Venter, J.G., K. Remington, J.F. Heidelberg, et al. 2004. Environmental genome shotgun sequencing of the Sargasso Sea. Science 304:66-74.

46. Watson, S.W. 1965. Characteristics of a marine nitrifying bacterium, Nitrosocystis oceanus sp. n. Limnol. Oceanogr. 10:R274-R289.

47. Widdel, F., G.W. Kohring, and F. Mayer. 1983. Studies on dissimilatory sulfate-reducing bacteria that decompose fatty acids. Arch. Microbiol. 134:286-294.

48. Wuchter, C., B. Abbas, M.J.L. Coolen, et al. 2006. Archaeal nitrification in the ocean. Proc. Natl. Acad. Sci. USA 103:1231712322. 